\title{
Alpha-Band Hypersynchronization in Progressive Mild Cognitive Impairment: A Magnetoencephalography Study
}

\author{
María Eugenía López, ${ }^{1,2 \star}$ Ricardo Bruña, ${ }^{1 *}$ Sara Aurtenetxe, ${ }^{1,2}$ José Ángel Pineda-Pardo, ${ }^{1,3}$ Alberto Marcos, ${ }^{4}$ \\ Juan Arrazola, ${ }^{5}$ Ana Isabel Reinoso, ${ }^{6}$ Pedro Montejo, ${ }^{6}{ }^{-}$Ricardo Bajo, ${ }^{1,7}$ and Fernando Maestú ${ }^{1,2}$ \\ ${ }^{1}$ Laboratories of Cognitive and Computational Neuroscience (Complutense University of Madrid-Universidad Politécnica of Madrid) and ${ }^{2}$ Department of \\ Basic Psychology II, Complutense University of Madrid (UCM), 28040 Madrid, Spain, ${ }^{3}$ Laboratory of Neuroimaging (Universidad Politécnica de Madrid) \\ (National Pedagogic University), Centre for Biomedical Technology (CTB), 28223 Madrid, Spain, Departments of ${ }^{4}$ Neurology and ${ }^{5}$ Radiology, San Carlos \\ University Hospital, 28040 Madrid, Spain, ${ }^{6}$ Centre for Prevention of Cognitive Impairment, Madrid Health, 28006, Madrid, Spain, and 7 Department of \\ Mathematics, International University of La Rioja (UNIR), 26006 Logroño, Spain
}

People with mild cognitive impairment (MCI) show a high risk to develop Alzheimer's disease (AD; Petersen et al., 2001). Nonetheless, there is a lack of studies about how functional connectivity patterns may distinguish between progressive (pMCI) and stable (sMCI) MCI patients. To examine whether there were differences in functional connectivity between groups, MEG eyes-closed recordings from 30 sMCI and $19 \mathrm{pMCI}$ subjects were compared. The average conversion time of pMCI was 1 year, so they were considered as fast converters. To this end, functional connectivity in different frequency bands was assessed with phase locking value in source space. Then the significant differences between both groups were correlated with neuropsychological scores and entorhinal, parahippocampal, and hippocampal volumes. Both groups did not differ in age, gender, or educational level. pMCI patients obtained lower scores in episodic and semantic memory and also in executive functioning. At the structural level, there were no differences in hippocampal volume, although some were found in left entorhinal volume between both groups. Additionally, pMCI patients exhibit a higher synchronization in the alpha band between the right anterior cingulate and temporo-occipital regions than $\mathrm{sMCI}$ subjects. This hypersynchronization was inversely correlated with cognitive performance, both hippocampal volumes, and left entorhinal volume. The increase in phase synchronization between the right anterior cingulate and temporo-occipital areas may be predictive of conversion from MCI to AD.

Key words: alpha band; anterior cingulate; functional connectivity; MEG; mild cognitive impairment; phase locking value

\section{Introduction}

Mild cognitive impairment (MCI) is an intermediate stage between the normal decline of aging and dementia (Petersen et al., 1999). $\mathrm{MCI}$ is considered as a pathological precursor of Alzheimer's disease (AD), because several longitudinal studies have found that the conversion rate from $\mathrm{MCI}$ to $\mathrm{AD}$ is $\sim 10-15 \%$ /year (Petersen et al., 2001). The early identification of those MCI patients who will convert to $\mathrm{AD}$ is essential to initiate an early treatment to slow down the devastating effects of this neurodegenerative disorder.

$\mathrm{AD}$ pathology is characterized by the presence of $\beta$-amyloid $(\mathrm{A} \beta)$ plaques, tau neurofibrillary tangles, and cortical and sub-

Received March 11, 2014; revised July 30, 2014; accepted Aug. 2, 2014.

Author contributions: M.E.L., R.Br., S.A., A.M., and F.M. performed research; M.E.L., R.Br., and R.Ba. analyzed data; M.E.L., R.Br., and F.M. wrote the paper; M.E.L., S.A., A.M., J.A., A.I.R., P.M., and F.M. designed research; J.Á.P.-P. contributed unpublished reagents/analytic tools.

This study was partially supported by Spanish Ministry of Science and Economy Grants PSI2009-14415-C03-01 and PSI2012-38375-C03-01, Ministry of Education Predoctoral Fellowships FPU AP-2008-00175 (M.E.L.) and AP2010-1317 (J.A.P.-P.), and a predoctoral fellowship from the Basque Government (S.A.). We thank Pablo Cuesta and Pilar Garcés for their help concerning the methods used in this work.

${ }^{*} M . E . L$. and R.Br. contributed equally to this work.

The authors declare no competing financial interests.

Correspondence should be addressed to María Eugenia López, Laboratory of Cognitive and Computational Neuroscience (Complutense University of Madrid-Universidad Politécnica of Madrid), Centre for Biomedical Technology, Campus de Montegancedo s/n, 28223 Pozuelo de Alarcón, Madrid, Spain. E-mail:meugenia.lopez@ctb.upm.es.

DOI:10.1523/JNEUROSCI.0964-14.2014

Copyright $\odot 2014$ the authors $\quad 0270-6474 / 14 / 3414551-09 \$ 15.00 / 0$ cortical atrophy (Trzepacz et al., 2014). Today, there are different approaches, many of them already focused on biomarkers, to identify those patients who would subsequently manifest AD. From a neuropsychological point of view, the performance in episodic memory tests has been proposed as the best predictor of conversion (Albert et al., 2007). Magnetic resonance imaging (MRI) studies have observed a hippocampal and entorhinal cortex atrophy in MCI patients progressing to $\mathrm{AD}$ [progressive MCI (pMCI); (deToledo-Morrell et al., 2004; Devanand et al., 2007]. Meanwhile, fluoro-deoxyglucose positron emission tomography (PET) studies have shown that pMCI patients present regional hypometabolism in the temporal, parietal, and/or precuneus cortices compared with MCI patients that remain stable [stable MCI (sMCI; Hatashita and Yamasaki, 2013]. Most of the Pittsburgh compound B (PIB)-PET studies show that PIB-positive MCI patients are significantly more likely to convert to AD than PIBnegative patients (Grimmer et al., 2013). In addition, some studies describe a decreased level of $\mathrm{A} \beta$ protein in CSF in pMCI patients compared with sMCI patients (Riemenschneider et al., 2002; Hampel et al., 2004). Conversely, an increase in tau protein levels in CSF in pMCI patients has been reported in several studies (Riemenschneider et al., 2002), with its predictive power even higher than in the case of $\mathrm{A} \beta$ (Hampel et al., 2004).

The predictive power of some of these methods is very heterogeneous, and those with high values of specificity and sensitivity 
are often limited by their high degree of invasiveness, reducing the likelihood of a daily clinical usage. Conversely, those methods with low invasiveness usually also obtain low classification values or do not explain the brain dynamics involved in this progression. Thus, there is a need for a non-invasive biomarker to do the following: (1) explore the brain regions that are affected in pMCI from a synchronization framework (previous functional connectivity studies with EEG/MEG were done in the sensor space; Bajo et al., 2012; Poil et al., 2013); and (2) combine information of brain damage (i.e., MR volumetry), functional network organization, and cognitive status. To the best of our knowledge, this is the first predictive resting-state MEG study in source space that combines neuropsychological, neurophysiological, and structural information to compare sMCI and pMCI patients. According to previous neurophysiological studies, we predict that pMCI patients will show a higher synchronization in high-frequency bands primarily over posterior brain areas compared with sMCI participants.

\section{Materials and Methods}

Subjects. The total sample of this experiment was recruited from the Neurology and Geriatric Departments of the University Hospital San Carlos (Madrid, Spain) and from the Centre for Prevention of Cognitive Impairment (Madrid, Spain). All the subjects were right handed (Oldfield, 1971), native Spanish speakers, and monitored over a 2 year follow-up period, with a clinical examination every 6 months.

The original sample consisted of $138 \mathrm{MCI}$ patients, and after a data inspection, we selected 98 subjects with clean MEG recordings. According to their clinical follow-up, they were divided in two subgroups: sMCI $(n=78)$ and pMCI (pMCI; $n=20)$ patients. Progressive patients who developed dementias different from $\mathrm{AD}$ (one case of frontotemporal dementia in our sample) were discarded, resulting in a homogeneous group of AD progressive patients $(n=19)$, with a rate of conversion to $\mathrm{AD}$ of $19.39 \%$.

To compare the differences between both groups with an adjusted number of the samples, we randomly selected $30 \mathrm{sMCI}$ patients from the original 98. The pMCI subjects of this study can be considered as faster converters, because the conversion time to $\mathrm{AD}$ was $\sim 1$ year after their MEG recordings, MRI scans, and their clinical and neurophysiological measurements (13.16 \pm 5.87 months, mean \pm SD; Okello et al., 2009). Therefore, the neurophysiological, structural, and neuropsychological comparisons made in this study between sMCI and pMCI subjects were based on the measures obtained when both groups were still MCI.

The two groups of participants were homogenized in age (mean sMCI age, 74.03 years; mean pMCI age, 76.68 years; Wilcoxon-Mann-Whitney test, $p=0.104$ ), gender (sMCI, 14 males, 16 females; pMCI: 8 males, 11 females; Fisher's exact test, $p=0.777$ ), and educational level (sMCI, 2.79; pMCI, 2.68; Wilcoxon-Mann-Whitney test, $p=0.934$ ).

Diagnostic criteria. The Mini Mental State Examination (MMSE; Lobo et al., 1979), the Geriatric Depression Scale-Short Form (Yesavage et al., 1982), the Global Deterioration Scale (Reisberg et al., 1982), the Hachinski Ischemic Score (Rosen et al., 1980), the functional assessment questionnaire (Pfeffer et al., 1982), the questionnaire for Instrumental Activities of Daily Living (Lawton and Brody, 1969), and the Global Deterioration Scale/Functional Assessment Staging Test (Auer and Reisberg, 1997) were used to establish the global cognitive and functional status of the patients.

MCI diagnosis was established according to the National Institute on Aging-Alzheimer Association (NIA-AA) criteria (Albert et al., 2011): (1) self- or informant-reported cognitive complaint; (2) objective evidence of impairment in one or more cognitive domains; (3) preserved independence in functional abilities; and (4) not demented (McKhann et al., 2011). Besides meeting the core clinical criteria for MCI, subjects had a positive biomarker reflecting neuronal injury, which was measured by MRI. So, all of them could be categorized MCI attributable to ADintermediate likelihood.
All subjects underwent an extensive neuropsychological assessment to evaluate their cognitive status in multiple areas with the following tests: clock drawing test (Agrell and Dehlin, 1998), direct and inverse digit spam test [Wechsler Memory Scale (WMS-III); Wechsler, 1997], immediate and delayed recall (WMS-III; Wechsler, 1997), phonemic and semantic fluency (controlled oral word association test; Benton and Hamsher, 1989), ideomotor praxis of Barcelona test (Peña-Casanova, 1990), rule shift cards (behavioral assessment of the dysexecutive syndrome; Norris and Tate, 2000), visual object and space perception test (Warrington and James, 1991), Boston naming test (Kaplan et al., 1983), and trail-making tests A and B (Reitan, 1958).

According to the cognitive testing, all of them were classified as amnestic MCI patients (Petersen et al., 2001) at baseline, and those who finally fulfilled the criteria for probable $\mathrm{AD}$ according to the guidelines of the NIA-AA (McKhann et al., 2011) at follow-up were considered as pMCI $(n=19)$.

The whole sample of MCI subjects was free of significant neurological or psychiatric diseases (other than $\mathrm{AD}$ or MCI) and medical treatment that could affect MEG activity (e.g., cholinesterase inhibitors). General inclusion criteria considered an age between 65 and 85 years, a modified Hachinski score $\leq 4$, a geriatric depression scale score $\leq 5$, and a T2weighted MRI within 12 months before MEG screening without indication of infection, infarction, or focal lesions (rated by two independent experienced radiologists; Bai et al., 2012). In addition, we performed on every participant complementary explorations (class II evidence level) to rule out possible causes of cognitive decline, such as B12 vitamin deficit, diabetes mellitus, thyroid problems, syphilis, or human immunodeficiency virus. Besides, those subjects with alcohol dependence (more than three alcoholic beverages per day) or chronic use of medication, such as anxiolytics, were not included in the experiment.

The study was approved by the local ethics committee and before the MEG recordings; a written informed consent was signed from all subjects or their legal representatives.

Hippocampal, parahippocampal, and entorhinal volumes. Hippocampal, parahippocampal, and entorhinal volumes were measured as anatomical evidences of brain atrophy characteristic for MCI and AD (Albert et al., 2011; McKhann et al., 2011). In addition, these measures have shown previously its predictive power in $\mathrm{AD}$ progression (Jack et al., 1999; deToledo-Morrell et al., 2004; Devanand et al., 2007). For most of the subjects included in this paper (23 sMCI and $14 \mathrm{pMCI})$, a T1- weighted MRI was available, acquired in a GE Healthcare 1.5 Tesla magnetic resonance scanner, using a high-resolution antenna and a homogenization pure filter (fast spoiled gradient echo sequence; repetition time, $11.2 \mathrm{~ms}$; echo time, $4.2 \mathrm{~ms}$; inversion time, $450 \mathrm{~ms}$; flip angle, $12^{\circ}$; $1 \mathrm{~mm}$ slice thickness; $256 \times 256$ matrix; and field of view, $25 \mathrm{~cm})$. These MRI images were processed with Freesurfer software (version 5.1.0) and its specialized tool for automated cortical and subcortical segmentation (Fischl et al., 2002) to obtain the volume of several brain areas. Finally, volumes were normalized with respect to the overall intracranial volume to account for differences in head volume over subjects.

$M E G$ recordings. Neurophysiological data was acquired by using a 306 channel (102 magnetometers, 204 planar gradiometers) Vectorview MEG system (Elekta), placed in a magnetically shielded room (VacuumSchmelze) at the Laboratory of Cognitive and Computational Neuroscience (Madrid, Spain). All recordings were obtained in the morning while subjects were sat comfortably, resting with eyes closed but awake. Three minutes of MEG signal was acquired for each subject.

Head shape was obtained by using a three-dimensional Fastrak digitizer (Polhemus) by acquiring three fiducial points (nasion and left and right preauricular points) and at least 300 points of the surface of the scalp. In addition, four head position indication (HPI) coils were placed in the subjects' head: two in the mastoids and two in the forehead. The position of the HPI coils was also acquired using the Fastrak device to provide continuous head position estimation during the recording. Finally, a vertical electrooculogram was placed near the left eye of the subjects to capture the blinks and eye movements.

MEG data were acquired using a sampling rate of $1000 \mathrm{~Hz}$ using an online anti-alias filter between 0.1 and $330 \mathrm{~Hz}$. Recordings were filtered offline using a tempo-spatial filtering algorithm (correlation window, 
0.9; time window, 10 s; Taulu and Kajola, 2005; Taulu and Simola, 2006) to subtract the sources of noise placed outside the head, and the head movements were corrected using the same algorithm.

The signal coming from the planar gradiometers was discarded, and only magnetometers were used in the subsequent analysis. Ocular, muscular, and jump artifacts were identified using an automatic procedure from the Fieldtrip package (Oostenveld et al., 2011) and were confirmed by an MEG expert. The remaining data were segmented in $4 \mathrm{~s}$ epochs of artifact-free activity. Only subjects with at least 15 segments were selected for additional analysis $(27.23 \pm 5.99$ epochs in the sMCI group, $26.11 \pm$ 6.73 epochs in the pMCI group, mean $\pm \mathrm{SD}$ ). In addition, an independent component analysis-based procedure was used to remove the electrocardiographic artifact when it was easily identified.

Artifact-free epochs were filtered in six frequency bands: delta (2-4 $\mathrm{Hz})$, theta $(4-8 \mathrm{~Hz})$, alpha $(8-12 \mathrm{~Hz})$, beta $1(12-20 \mathrm{~Hz})$, beta $2(20-30$ $\mathrm{Hz})$, and gamma $(30-45 \mathrm{~Hz})$, using a 1500 order finite impulse response filter with Hamming window and a two-pass filtering procedure. The segments were padded with $1.75 \mathrm{~s}$ of real signal from both sides (1750 samples) to prevent edge effects inside the data.

Source reconstruction. A source reconstruction analysis was performed independently for each band, using a linearly constrained minimum variance beam former (Van Veen et al., 1997). Because we did not have a T1 MRI for all subjects, a $1 \mathrm{~mm}$ resolution template of healthy adults (52 subjects, aged $69.9 \pm 4.4$ years, mean $\pm \mathrm{SD}$ ) normalized to the Montreal Neurological Institute (MNI) $1 \mathrm{~mm}$ voxel size template was used to place the sources inside the brain. T1 images were coregistered to the MNI T1 template (available in SPM5, http://www.fil.ion.ucl.ac.uk/spm/software/ spm5/) using linear affine registration with normalized mutual information as fitness function (Collignon and Maes, 1995). The registered images were normalized to the MNI template using a nonlinear registration algorithm (Ashburner, 2007) and then smoothed with a Gaussian kernel with full-width half-maximum of $4 \mathrm{~mm}$. The resulting normalized images were averaged across subjects to obtain a template, which was used to define a homogeneous grid of $1 \mathrm{~cm}$. Then both the template and grid were linearly transformed to fit the head shape of each subject.

The lead fields were defined using a local spheres approach to fit the head shape of each subject in the vicinity of each sensor. Spatial filter coefficients were estimated for each subject using the computed lead field and an average of the covariance matrix for all the segments. Thereafter, this filter was used to compute the source time series separately for each segment and source location.

Sources were grouped according to the 96-area Harvard-Oxford cortical map, assigning each source location to the most probable area given its position. From the original 3431 source locations, only those 1681 labeled as belonging to an area defined in the atlas were considered in the following steps. The other 1750 sources were placed in areas not defined in the atlas (i.e., white matter, CSF, or subcortical regions) and therefore cannot be source generators of MEG signals (Hämäläinen et al., 1993).

Connectivity analysis. The analysis of the connectivity was performed using the hypothesis of phase synchronization (Rosenblum et al., 2001) evaluated by means of the phase locking value (PLV; Lachaux et al., 1999). Phase synchronization measures are based on the hypothesis that the difference of phases between two phase-locked systems must be nonuniform, and so the degree of non-uniformity must be a good estimator of the coupling level.

In the PLV, the degree of non-uniformity is calculated by defining as many vectors as temporal points, each one with unity norm and phase equal to the difference of phases of both systems for this temporal point. The norm of the mean vector is the PLV, ranging from 0 , when the differences of phases are uniformly distributed, to values near 1 , when the phases are concentrated in a small portion of the available range. The formal definition for the PLV between two systems, $i$ and $j$, with instantaneous phases $\varphi_{i}(t)$ and $\varphi_{j}(t)$, is (Lachaux et al., 1999) as follows:

$$
\operatorname{PLV}_{i, j}=\left|\frac{1}{T} \sum_{t} e^{2 \pi j\left(\varphi_{i}(t)-\varphi_{j}(t)\right)}\right| .
$$

To reduce the dimensionality of the information, we estimated the synchronization between each pair of areas of the Harvard-Oxford cortical atlas. We can consider each area as a system and each source position inside the area as a noise-contaminated realization of the system. For each pair of areas, area $i$ with $M_{i}$ sources and area $j$ with $M_{j}$ sources, we can create $M_{i}$ by $M_{j}$ combinations of sources for each segment, leading to $M_{i}$ by $M_{j}$ repetitions of the experiment. All these repetitions are time locked; thus, the total synchronization can be obtained as the norm of the mean vector for all the repetitions.

Conversely, different segments are not time locked, because in the resting state, there is no triggering event that resets the phases (Lachaux et al., 1999). We can then average the synchronization value of all the $K$ segments for each pair of areas, obtaining a consistent indicator of the level of coupling between the areas. Formally, this PLV index between the areas $i$ and $j$ is calculated as follows:

$$
\operatorname{PLV}_{i, j}=\frac{1}{K} \sum_{K}\left|\frac{1}{M_{i} \times M_{j} \times T} \sum_{M_{i}} \sum_{M_{j}} \sum_{T} e^{2 \pi j\left(\varphi_{m_{i}}(t, k)-\varphi_{m_{j}}(t, k)\right)}\right|,
$$

where $\varphi_{m}(t, k)$ represents the instantaneous phase the time series $i$ of the area $m$ for the instant $t$ of the segment $k$. In this work, the instantaneous phase of the signal in each band was calculated from the phase of the analytic signal of the narrow band data, obtained using the Hilbert transform (Pereda et al., 2005).

Statistical analysis. To assess the significant differences in functional connectivity measures, we performed a Mann-Whitney $U$ nonparametric test using the PLVs estimated for each pair of areas. To correct the multiple comparisons problem, we first performed a nonparametric permutation test, keeping the size of the groups but randomly permuting their members (10,000 permutations). The $p$ value obtained in this step represents the portion of permutations in which the $U$ statistic was greater than that in the original dataset.

Then a false discovery rate (FDR; Benjamini and Hochberg, 1995) with $q=0.1$ (a $10 \%$ false-positive probability) was used to reduce the portion of false positives in the obtained $p$ value distribution. Only the links that survived the FDR are reported in Results. In addition, a Spearman's correlated test was performed between connectivity values in these links and neuropsychological and structural data to better understand its significance.

Finally, a classification analysis was performed using the variables that showed significant differences between both groups by using a logistic regression analysis with the leave-one-out cross-validation procedure. Results are described in terms of accuracy, sensitivity, specificity, positive predictive value (PPV), and negative predictive value (NPV). Accuracy value represents the fraction of subjects classified correctly. Sensitivity and specificity values represent the fractions of $\mathrm{pMCI}$ and sMCI patients correctly classified, respectively. Finally, PPVs and NPVs represent the fraction of patients classified as pMCI that were really pMCI and the fraction of patients classified as sMCI that were really sMCI, respectively. When reporting accuracy values, the information is completed with a confidence interval (CI) for the statistic, calculated using the $\beta$ approach (Clopper and Pearson, 1937).

\section{Results}

Because the clinical criteria of AD, according to the National Institute of Neurological and Communicative Diseases and Stroke-Alzheimer's Disease and Related Disorders Association, are based on cognitive or behavioral symptoms, our first approach was to evaluate the predictive capacity of the functional and cognitive measures to discriminate between sMCI and pMCI. Table 1 shows the statistical values associated with each cognitive measurement and with volumes of the temporal region. MMSE scores showed no differences between groups. In contrast, both groups of patients did differ in immediate $(p=3.26 \times$ $\left.10^{-6}\right)$ and delayed $\left(p=7.18 \times 10^{-5}\right)$ recall, rule shift cards $(p=$ $0.028)$, and semantic fluency $(p=0.041)$. The values obtained by each group in these four neuropsychological measures are depicted in Figure 1. A classification analysis was performed for each one of the two most significant, achieving classification rates 
Table 1. Demographic, anatomical, and neuropsychological information

\begin{tabular}{|c|c|c|c|}
\hline & sMCl patients $(n=30)$ & pMCl patients $(n=19)$ & $p$ values \\
\hline Age (years) & $74.0 \pm 5.3$ & $76.7 \pm 5.3$ & 0.104 \\
\hline Gender (males/females) & $14 / 16$ & $8 / 11$ & 0.777 \\
\hline Educational level & $2.8 \pm 1.3$ & $2.7 \pm 1.0$ & 0.934 \\
\hline MMSE score & $27.9 \pm 1.9$ & $27.4 \pm 2.0$ & 0.455 \\
\hline GDS & $3.0 \pm 0.0$ & $3.0 \pm 0.0$ & 1.000 \\
\hline FAQ & $1.9 \pm 1.8$ & $1.8 \pm 2.8$ & 0.501 \\
\hline GDS-SF & $3.8 \pm 3.1$ & $3.5 \pm 3.8$ & 0.647 \\
\hline Immediate recall & $20.7 \pm 8.2$ & $10.0 \pm 5.0$ & $3.26 \times 10^{-6 *}$ \\
\hline Delayed recall & $8.6 \pm 7.4$ & $1.8 \pm 2.2$ & $7.18 \times 10^{-5 *}$ \\
\hline Rule shift cards & $2.4 \pm 1.3$ & $1.6 \pm 1.2$ & $0.028^{*}$ \\
\hline Semantic fluency & $13.0 \pm 2.8$ & $11.6 \pm 4.4$ & $0.041^{*}$ \\
\hline Phonemic fluency & $10.8 \pm 4.2$ & $8.8 \pm 4.1$ & 0.119 \\
\hline BNT & $50.4 \pm 10.7$ & $46.3 \pm 9.4$ & 0.510 \\
\hline Clock drawing test (copy) & $7.6 \pm 2.6$ & $8.0 \pm 4.2$ & 0.600 \\
\hline Clock drawing test (order) & $6.4 \pm 2.6$ & $7.4 \pm 3.6$ & 0.615 \\
\hline Direct digit spam & $6.7 \pm 1.6$ & $6.4 \pm 1.5$ & 0.413 \\
\hline Inverse digit spam & $4.7 \pm 1.3$ & $4.0 \pm 1.4$ & 0.103 \\
\hline VOSP & $6.7 \pm 3.5$ & $7.2 \pm 3.1$ & 0.593 \\
\hline TMTA (time) & $78.7 \pm 36.0$ & $82.8 \pm 33.6$ & 0.580 \\
\hline TMTA (accuracy) & $24.0 \pm 0.6$ & $23.8 \pm 1.8$ & 0.401 \\
\hline TMTB (time) & $223.2 \pm 107.8$ & $258.4 \pm 121.7$ & 0.329 \\
\hline TMTB (accuracy) & $20.1 \pm 4.8$ & $15.2 \pm 8.6$ & 0.050 \\
\hline Ideomotor praxis & $7.3 \pm 1.7$ & $7.2 \pm 1.1$ & 0.374 \\
\hline Left hippocampal volume & $0.002217 \pm 0.000508$ & $0.001992 \pm 0.000254$ & 0.056 \\
\hline Right hippocampal volume & $0.002197 \pm 0.000466$ & $0.001965 \pm 0.000388$ & 0.063 \\
\hline Left entorhinal volume & $0.000527 \pm 0.000100$ & $0.000452 \pm 0.000106$ & $0.038^{*}$ \\
\hline Right entorhinal volume & $0.000481 \pm 0.000072$ & $0.000452 \pm 0.000155$ & 0.954 \\
\hline Left parahippocampal volume & $0.000663 \pm 0.000072$ & $0.000596 \pm 0.000169$ & 0.153 \\
\hline Right parahippocampal volume & $0.000645 \pm 0.000113$ & $0.000604 \pm 0.000175$ & 0.864 \\
\hline
\end{tabular}

Mean \pm SD values of the demographic and clinical characteristics of the SMCl and pMCI patients. MMSE, Mini Mental State Examination; GDS, Global Deterioration Scale; FAQ, Functional Activity Questionnaire; GDS-SF, Geriatric Depression Scale-Short Form; BNT, Boston Naming Test; VOSP, Visual Object and Space Perception Battery; TMTA, Trail-Making Test part A; TMTB, Trail-Making Test part B. Educational level was grouped into five levels: 1, illiterate; 2, primary studies; 3 , elemental studies; 4 , high school studies; 5 , university studies. $p$ values for between-groups differences were introduced, and ${ }^{*} p<0.05$. Wilcoxon-Mann-Whitney test was used for continuous variables (age, educational level, MMSE, or immediate and delayed recall) and Fisher's exact test for gender differences.
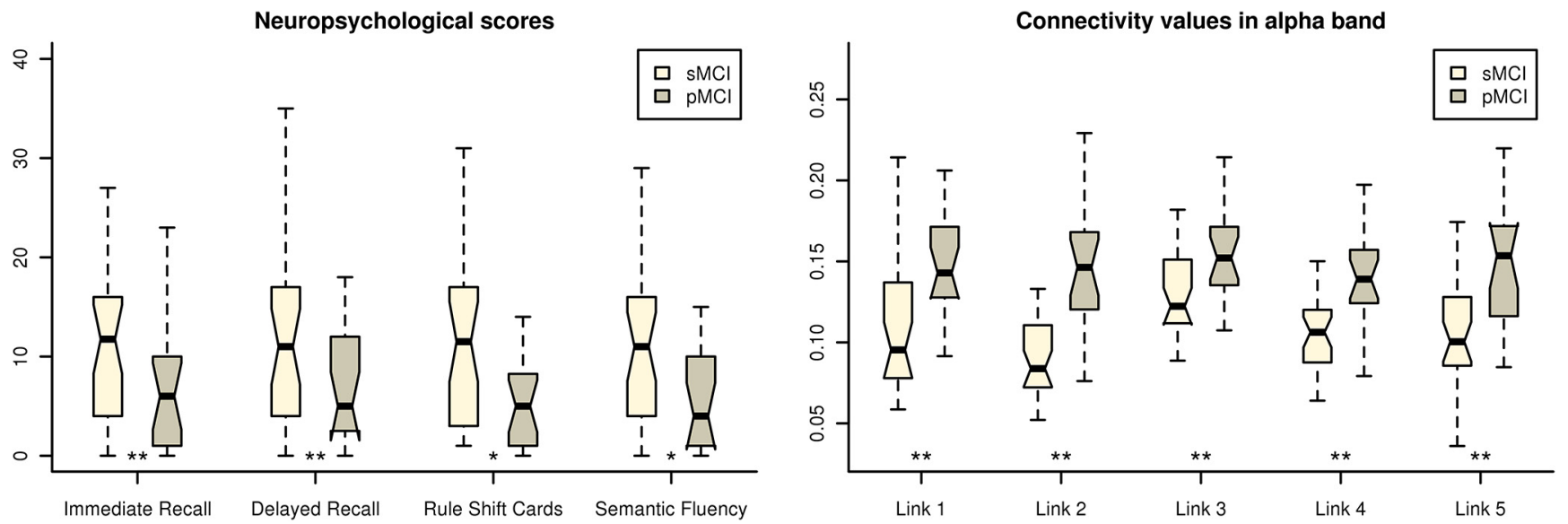

Figure 1. Box plots depicting the behavior of the subjects for each group. Left, Scores achieved by the subjects in the four statistically significant neuropsychological tests. Right, Connectivity values for the subjects in the five statistically significant links. ${ }^{*} p<0.05,{ }^{* *} p<0.001$.

of $79.6 \%$ for immediate recall $(95 \% \mathrm{CI}=65.7-89.8 \%, 84.2 \%$ sensitivity, $76.7 \%$ specificity, $69.6 \% \mathrm{PPV}, 88.5 \% \mathrm{NVP})$ and $77.6 \%$ for delayed recall $(95 \% \mathrm{CI}=63.4-88.2 \%, 78.9 \%$ sensitivity, $76.7 \%$ specificity, $68.2 \%$ PPV, $85.2 \%$ NPV). Conversely, the pMCI group exhibited lower left entorhinal volume than the sMCI group ( $p=0.038$ ), but no differences were found in either the parahippocampal or hippocampal volumes $(p>0.05)$.

The functional connectivity analysis exhibited no significant differences between groups after the FDR in delta, theta, beta 1, beta 2, or gamma bands. In contrast, FDR analysis in the alpha band showed five significant links between the right anterior cingulate gyrus and right middle temporal gyrus and occipital regions, mainly in the right hemisphere. In all these links, pMCI patients showed significantly greater connectivity values than sMCI patients $\left(p<10^{-3}\right)$. Figure 1 represents the connectivity values obtained for each group, Figure 2 depicts the position and size of all six regions implied in these links, and Table 2 shows the $p$ value of each one of the five significant links. Afterward, a classification analysis was performed individually for each link, achieving a maximal classification rate in link 2 (right lateral 

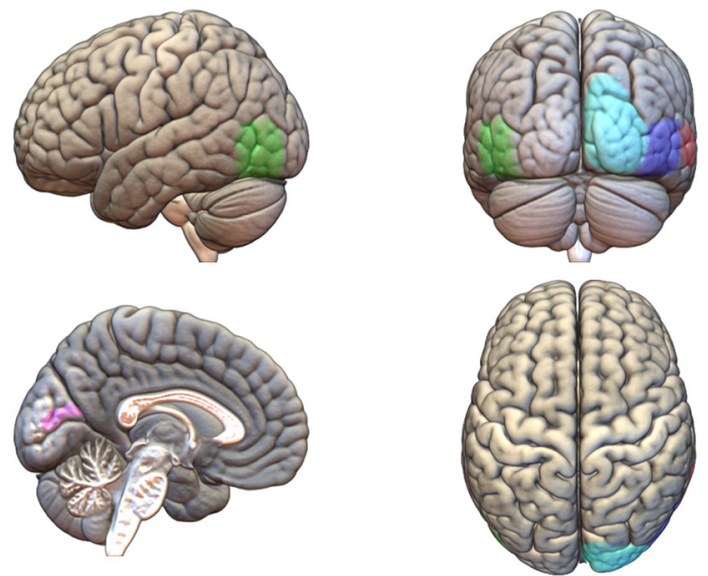

A

* Right Cingulate Gyrus, anterior division

1. Right Middle Temporal Gyrus

2. Right Lateral Occipital Cortex, inferior division

3. Right Occipital Pole

4. Left Supracalcarine Cortex

5. Left Lateral Occipital Cortex, inferior division

\section{B}

Figure 2. Cortical areas implied in the five connectivity links that showed significant differences between groups. $A$, Different views of the brain based on the MNI template and Harvard-0xford cortical areas involved in those links. $\boldsymbol{B}$, Relation of areas, numbers, and colors. C, Significant connectivity links established between those areas.

occipital cortex, inferior division, with right cingulate gyrus, anterior division) with an accuracy of $81.6 \%$ (95\% CI $=68.0-$ 91.2\%, 84.2\% sensitivity, $80.0 \%$ specificity, $72.7 \%$ PPV, $88.9 \%$ NPV). All classification statistics are also shown in Table 2.

To better describe our functional connectivity findings, we performed a Spearman's correlation test between connectivity values in those links, neuropsychological punctuations, and volumetric data. We found an inverse significant correlation $(p<$ 0.05 ) between some of these links and MMSE, immediate recall, and semantic fluency scores. Moreover, we observed inverse significant correlations $(p<0.05)$ between several links, both hippocampus volumes and left entorhinal volume. Table 3 details all these findings along with their significance level.

Finally, with the aim of evaluating the combined predictive power of both neuropsychological and neurophysiological data in terms of conversion, we performed a classification analysis using as variables those with higher classification statistics: immediate recall scores and link 2 connectivity values. The accuracy achieved combining both measures was $89.8 \%$ (95\% CI $=77.8-$ 96.6\%, 89.5\% sensitivity, 90.0\% specificity, $85.0 \%$ PPV, $93.1 \%$ NPV), greater than if these two variables were considered separately.

\section{Discussion}

This study provides a specific pattern of functional network organization in resting state in those MCI patients who developed dementia. pMCI patients showed an increase in functional connectivity values in the alpha band between the anterior and posterior brain areas and more specifically between the right anterior cingulate and temporo-occipital areas.

Previous resting state EEG studies found different markers of progression to AD. Jelic et al. (2000) reported that the best pre-
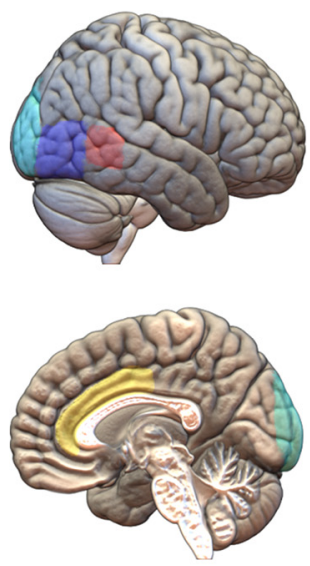

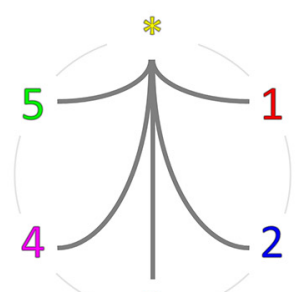

3 dictor of future conversion from MCI to $\mathrm{AD}$ was an increased theta power and a decrease in alpha activity, whereas Huang et al. (2000) evidenced that the best predictor was the shift of alpha activity toward anterior brain. Rossini et al. (2006) found that pMCI patients exhibit higher power values in the delta, theta, and alpha 1 bands, mainly over temporal and parietal areas, and also changes in frontoparietal midline coherence values. More recently, Moretti et al. (2011) observed that those MCI patients who convert to $\mathrm{AD}$ presented an increase in the alpha3/ alpha 2 relative power ratio, with this ratio further related to hippocampal atrophy (Moretti et al., 2007). Poil et al. (2013) reported that multiple EEG biomarkers were mainly related to activity in the betafrequency range, which was higher in the pMCI group than in the sMCI group.

Surprisingly, there are very few MEG studies about the MCI progression to AD. A resting-state MEG study by Fernández et al. (2006) found that an increase in delta activity in the left parietal areas was a good marker of conversion within 2 years. Furthermore, Maestú et al. (2011) observed that, during the performance of a shortterm memory task, pMCI patients showed higher activity in the ventral and dorsal pathways than sMCI subjects. Afterward, and under the same memory paradigm, Bajo et al. (2012) described that pMCI patients exhibited higher values of synchronization over parieto-occipital sensors in the alpha and beta 1 bands than sMCI patients.

Our connectivity results seem to be in agreement with those obtained by Rossini et al. (2006) and Bajo et al. (2012), because they reported an increase in connectivity measures in the pMCI subjects compared with the sMCI group. Although the increase in synchronization observed in MCIs has been interpreted usually as a compensatory mechanism, the negative correlations found in this study with neuropsychological performance and temporal brain volumes could lead us to consider two possible hypothesis about this hypersynchronization: (1) it could be an unsuccessful compensation: the right anterior cingulate along with temporal and occipital regions try to assume the functions of other brain circuits that are more impaired (i.e., involving the posterior cingulate) but in an inefficient way; or (2) it could be the result of an inhibitory deficit: the loss of GABAergic synapses caused by the accumulation of $\mathrm{A} \beta$ plaques (Garcia-Marin et al., 2009) leads it to establish aberrant relationships between areas that start to be affected as the disease progresses.

The anterior cingulate is a region of the mediofrontal circuit that has been related to conflict monitoring, decision making, and affective behavior, among other functions (Devinsky et al., 1995). A relationship between its alteration in AD patients and inhibition disabilities, unawareness of deficits, and apathy has been found (Amanzio et al., 2011; Mori et al., 2014). The executive and inhibitory deficits found even in pure amnestic MCI patients may also be attributable to the damage of this brain structure (Kramer et al., 2006; Johns et al., 2012). In addition, some MRI, single-photon emission computed tomography, and 
Table 2. The five significant links in the alpha band between sMCl and pMCl patients were obtained with a Mann-Whitney $U$ test after the FDR

\begin{tabular}{|c|c|c|c|c|c|c|c|c|}
\hline & \multirow[b]{2}{*}{ sMCl patients $(n=30)$} & \multirow[b]{2}{*}{ pMCl patients $(n=19)$} & \multirow[b]{2}{*}{$p$ values } & \multicolumn{5}{|c|}{ Classification statistics (\%) } \\
\hline & & & & $\mathrm{ACC}(95 \% \mathrm{Cl})$ & SEN & SPE & PPV & NPV \\
\hline Link 1 & $0.11 \pm 0.03$ & $0.14 \pm 0.02$ & $2.04 \times 10^{-4}$ & $77.6(63.4-88.2)$ & 78.9 & 76.7 & 68.2 & 85.2 \\
\hline Link 2 & $0.10 \pm 0.03$ & $0.14 \pm 0.03$ & $3.40 \times 10^{-5}$ & $81.6(68.0-91.2)$ & 84.2 & 80.0 & 72.7 & 88.9 \\
\hline Link 4 & $0.14 \pm 0.03$ & $0.18 \pm 0.03$ & $1.35 \times 10^{-4}$ & $77.6(63.4-88.2)$ & 78.9 & 76.7 & 68.2 & 85.2 \\
\hline Link 5 & $0.10 \pm 0.03$ & $0.14 \pm 0.03$ & $2.81 \times 10^{-4}$ & $69.4(54.6-81.7)$ & 68.4 & 70.0 & 59.1 & 77.8 \\
\hline
\end{tabular}

Link 1, right cingulate gyrus, anterior division, with right middle temporal gyrus, temporo-occipital part; Link 2, right cingulate gyrus, anterior division, with right lateral occipital cortex, inferior division; Link 3, right cingulate gyrus, anterior division, with right occipital pole; Link 4, right cingulate gyrus, anterior division, with left supracalcarine cortex; Link 5, right cingulate gyrus, anterior division, with left lateral occipital cortex, inferior division; ACC, accuracy; SEN, sensitivity; SPE, specificity; PPV, positive predictive value; NPV, negative predictive value; $95 \% \mathrm{Cl}, 95 \%$ confidence interval.

Table 3. Spearman's correlation analyses of the five significant links obtained in the alpha band with neuropsychological test scores and hippocampal volumes in the whole sample

\begin{tabular}{|c|c|c|c|c|c|}
\hline & Link 1 & Link 2 & Link 3 & Link 4 & Link 5 \\
\hline \multirow[t]{2}{*}{ MMSE } & $r=-0.195$ & $r=-0.300$ & $r=-0.207$ & $r=-0.143$ & $r=-0.097$ \\
\hline & n.s. & $p=0.047$ & n.s. & n.s. & n.s. \\
\hline \multirow[t]{2}{*}{ Immediate recall } & $r=-0.268$ & $r=-0.394$ & $r=-0.366$ & $r=-0.300$ & $r=-0.350$ \\
\hline & n.s. & $p=0.005$ & $p=0.010$ & $p=0.036$ & $p=0.014$ \\
\hline \multirow[t]{2}{*}{ Semantic fluency } & $r=-0.172$ & $r=-0.286$ & $r=-0.264$ & $r=-0.145$ & $r=-0.135$ \\
\hline & n.s. & $p=0.047$ & n.s. & n.s. & n.s. \\
\hline \multirow[t]{2}{*}{ Left hippocampal volume } & $r=-0.322$ & $r=-0.370$ & $r=-0.170$ & $r=-0.336$ & $r=-0.213$ \\
\hline & $p=0.046$ & $p=0.020$ & n.s. & $p=0.036$ & n.s. \\
\hline \multirow[t]{2}{*}{ Right hippocampal volume } & $r=-0.223$ & $r=-0.302$ & $r=-0.342$ & $r=-0.368$ & $r=-0.431$ \\
\hline & n.s. & n.s. & $p=0.033$ & $p=0.021$ & $p=0.006$ \\
\hline \multirow[t]{2}{*}{ Left entorhinal volume } & $r=-0.374$ & $r=-0.411$ & $r=-0.209$ & $r=-0.475$ & $r=-0.318$ \\
\hline & $p=0.021$ & $p=0.010$ & n.s. & $p=0.003$ & n.s. \\
\hline
\end{tabular}

Shown are the $r$ (correlation index) and $p$ values that were significant $(p<0.05)$. MMSE, Mini Mental State Examination.

PIB-PET studies pointed out that this densely connected region might be key during the evolution of AD. Peters et al. (2014) found that one of the best predictors of the conversion from MCI to $\mathrm{AD}$ after 2 years was the cortical thinning in the right anterior cingulate. Johnson et al. (2007) reported an more increased perfusion in pMCI patients than in sMCI patients within a 5 year follow-up period in the rostral anterior cingulate. Recently, Okello et al. (2009) found that faster converters (average of 1 year, as our patients) showed a higher amyloid deposition in the anterior cingulate than slow converters. These findings would be in agreement with the idea that the hyperactivation observed in this brain region is attributable to the loss of inhibitory synapses, caused by the accumulation of A $\beta$ (Garcia-Marin et al., 2009).

One of the main finding in $\mathrm{AD}$ studies is the decrease in synchronization in high-frequency bands, especially in alpha (Locatelli et al., 1998; Berendse et al., 2000), so the hypersynchronization usually observed in pMCI patients seems to be paradoxical. However, the synaptic disruption produced in the cholinergic system (Requena et al., 2006; Schliebs and Arendt, 2006) and the loss of inhibitory neurons caused by the accumulation of neuritic plaques (Garcia-Marin et al., 2009) may produce the increase in synchronization in high oscillations in these patients. The synchronization found in the alpha band over the occipital cortex is consistent with the eyes-closed resting-state condition. The occipital lobe has usually been considered less impaired or not prominently involved until the last stages of the $\mathrm{AD}$, but there is evidence of amyloid pathology in MCI patients and even in healthy subjects (McKee et al., 2006; Uhlhaas et al., 2008). Thus, our results suggest that the occipital lobe appears to be part of a disrupted network in which pMCI patients present a higher amyloid pathology than sMCI subjects.

Several studies have also described an increase of synchronization in the alpha band in MCI subjects while performing a cognitive task compared with controls (Pijnenburg et al., 2004;
Jiang and Zheng, 2006; Bajo et al., 2010). Therefore, we speculated that, as the disease progresses, the hypersynchronization observed in MCI patients would lead to neuronal death, causing the disruption observed in more advance stages of the AD (Locatelli et al., 1998; Koenig et al., 2005; Stam et al., 2009).

In line with previous studies, pMCI patients showed a worse performance in episodic memory, which was the cognitive area with higher classification rates (Albert et al., 2007), but also in semantic memory and executive functioning. These findings suggest that extra-memory cognitive impairments may also have a role in the prediction of the progression from MCI to AD (Chapman et al., 2011). In addition, the hypersynchronization exhibited by pMCI patients was inversely correlated with different neuropsychological scores, indicating that it has a negative effect on memory and general cognitive status of patients.

At the structural level, there were no differences in either parahippocampal or hippocampal volumes between sMCI and pMCI patients (Peters et al., 2014), although the left hippocampus was slightly smaller in the pMCI patients, which is in accordance with previous studies (Douaud et al., 2013). However, pMCI patients exhibited a significant reduction of the left entorhinal volume. It is considered that, in this brain structure, the $\mathrm{AD}$ pathology begins (Khan et al., 2014) and that it is the interface between the hippocampus and the neocortex that has a critical role in memory (Takehara-Nishiuchi, 2014). Therefore, the differences obtained in verbal memory between both groups may be explained by the higher atrophy observed in the pMCI group, although it is important to note that the deficits in executive functioning exhibited by this group may influence verbal memory performance (Brooks et al., 2006; Chang et al., 2010). Notwithstanding that hippocampal atrophy is one of the anatomical changes that better predicts the subsequent conversion to AD (Jack et al., 1999), our anatomical results seem to be consistent with the role of the entorhinal cortex at the onset of $\mathrm{AD}$, because our pMCI patients 
were faster converters and there was greater involvement of the entorhinal than the parahippocampal cortex in predicting the conversion to AD (Devanand et al., 2007). The increase in synchronization showed by pMCI subjects was negatively related to both hippocampal volumes and left entorhinal volume, indicating that this increment reflect higher atrophy of these brain structures, which are more vulnerable to AD.

Finally, the higher classification scores obtained in the hypersynchronized links separately or combined with neuropsychological information are similar, or even better, than those obtained previously (Poil et al., 2013; Belleville et al., 2014; Peters et al., 2014). These findings suggest that MEG functional network organization is able to detect the functional changes caused by synaptic disruption that precede the structural ones.

Together, this work shows MEG as a promising biomarker of synaptic disruption in the prediction of the AD and the importance of combining it with other measures (Lehmann et al., 2007; Poil et al., 2013) to development a predictive model of AD (Antila et al., 2013). Forthcoming studies should go further and focus on predicting future cognitive decline in healthy subjects with and without subjective memory complaints (Prichep et al., 2006) to initiate preventive treatments at the earliest possible time.

The study of brain connectivity is allowing us a better understanding of how our mind works to achieve a good cognitive performance (Hampson et al., 2006) and how the disease causes its disruption to affect the cognitive status of the patients (de Haan et al., 2012). Therefore, the present work provides a new perspective in addressing the evolution of $\mathrm{AD}$ and reinforces the $\mathrm{MEG}$ as an important biomarker to evaluate $\mathrm{AD}$ progression.

\section{References}

Agrell B, Dehlin O (1998) The clock-drawing test. Age Ageing 27:399-403. CrossRef

Albert M, Blacker D, Moss MB, Tanzi R, McArdle JJ (2007) Longitudinal change in cognitive performance among individuals with mild cognitive impairment. Neuropsychology 21:158-169. CrossRef Medline

Albert MS, DeKosky ST, Dickson D, Dubois B, Feldman HH, Fox NC, Gamst A, Holtzman DM, Jagust WJ, Petersen RC, Snyder PJ, Carrillo MC, Thies B, Phelps CH (2011) The diagnosis of mild cognitive impairment due to Alzheimer's disease: recommendations from the National Institute on Aging-Alzheimer's Association workgroups on diagnostic guidelines for Alzheimer's disease. Alzheimers Dement 7:270-279. CrossRef Medline

Amanzio M, Torta DME, Sacco K, Cauda F, D’Agata F, Duca S, Leotta D, Palermo S, Geminiani GC (2011) Unawareness of deficits in Alzheimer's disease: role of the cingulate cortex. Brain 134:1061-1076. CrossRef Medline

Antila K, Lötjönen J, Thurfjell L, Laine J, Massimini M, Rueckert D, Zubarev RA, Orešič M, van Gils M, Mattila J, Hviid Simonsen A, Soininen H, Ores M, Waldemar G (2013) The PredictAD project: development of novel biomarkers and analysis software for early diagnosis of the Alzheimer's disease. Interface Focus 3:20120072. CrossRef Medline

Ashburner J (2007) A fast diffeomorphic image registration algorithm. Neuroimage 38:95-113. CrossRef Medline

Auer S, Reisberg B (1997) The GDS/FAST staging system. Int Psychogeriatr 9 [Suppl 1]:167-171.

Bai F, Shu N, Yuan Y, Shi Y, Yu H, Wu D, Wang J, Xia M, He Y, Zhang Z (2012) Topologically convergent and divergent structural connectivity patterns between patients with remitted geriatric depression and amnestic mild cognitive impairment. J Neurosci 32:4307-4318. CrossRef Medline

Bajo R, Maestú F, Nevado A, Sancho M, Gutiérrez R, Campo P, Castellanos NP, Gil P, Moratti S, Pereda E, Del-Pozo F (2010) Functional connectivity in mild cognitive impairment during a memory task: implications for the disconnection hypothesis. J Alzheimers Dis 22:183-193. CrossRef Medline

Bajo R, Castellanos NP, Cuesta P, Aurtenetxe S, Garcia-Prieto J, Gil-Gregorio P, del-Pozo F, Maestu F (2012) Differential patterns of connectivity in progressive mild cognitive impairment. Brain Connect 2:21-24. CrossRef Medline
Belleville S, Gauthier S, Lepage E, Kergoat MJ, Gilbert B (2014) Predicting decline in mild cognitive impairment: a prospective cognitive study. Neuropsychology 28:643-652. CrossRef Medline

Benjamini Y, Hochberg Y (1995) Controlling the false discovery rate: a practical and powerful approach to multiple testing. J R Stat Soc Ser B 57:289-300.

Benton AL, Hamsher K (1989) Multilingual aphasia examination manual. Iowa City, IA: University of Iowa.

Berendse HW, Verbunt JP, Scheltens P, van Dijk B, Jonkman EJ (2000) Magnetoencephalographic analysis of cortical activity in Alzheimer's disease: a pilot study. Clin Neurophysiol 111:604-612. CrossRef Medline

Brooks BL, Weaver LE, Scialfa CT (2006) Does impaired executive functioning differentially impact verbal memory measures in older adults with suspected dementia? Clin Neuropsychol 20:230-242. CrossRef Medline

Chang YL, Jacobson MW, Fennema-Notestine C, Hagler DJ Jr, Jennings RG, Dale AM, McEvoy LK (2010) Level of executive function influences verbal memory in amnestic mild cognitive impairment and predicts prefrontal and posterior cingulate thickness. Cereb Cortex 20:1305-1313. CrossRef Medline

Chapman RM, Mapstone M, McCrary JW, Gardner MN, Porsteinsson A, Sandoval TC, Guillily MD, Degrush E, Reilly LA (2011) Predicting conversion from mild cognitive impairment to Alzheimer's disease using neuropsychological test and multivariate methods. J Clin Exp Neuropsychol 33:187-199. CrossRef Medline

Clopper C, Pearson E (1937) The use of confidence or fiducial limits illustrated in the case of the binomial. Biometrika 26:404-413.

Collignon A, Maes F (1995) Automated multi-modality image registration based on information theory. Proc Inf Process Med Imaging:263-274.

de Haan W, van der Flier WM, Wang H, Van Mieghem PF, Scheltens P, Stam CJ (2012) Disruption of functional brain networks in AD: what can we learn from graph spectral analysis of resting-state magnetoencephalography? Brain Connect 2:45-55. CrossRef Medline

deToledo-Morrell L, Stoub TR, Bulgakova M, Wilson RS, Bennett DA, Leurgans S, Wuu J, Turner DA (2004) MRI-derived entorhinal volume is a good predictor of conversion from MCI to AD. Neurobiol Aging 25: 1197-1203. CrossRef Medline

Devanand DP, Pradhaban G, Liu X, Khandji A, De Santi S, Segal S, Rusinek H, Pelton GH, Honig LS, Mayeux R, Stern Y, Tabert MH, de Leon MJ (2007) Hippocampal and entorhinal atrophy in mild cognitive impairment: prediction of Alzheimer disease. Neurology 68:828-836. CrossRef Medline

Devinsky O, Morrell MJ, Vogt BA (1995) Contributions of anterior cingulate cortex to behaviour. Brain 118:279-306. CrossRef Medline

Douaud G, Menke RA, Gass A, Monsch AU, Rao A, Whitcher B, Zamboni G, Matthews PM, Sollberger M, Smith S (2013) Brain microstructure reveals early abnormalities more than two years prior to clinical progression from mild cognitive impairment to Alzheimer's disease. J Neurosci 33: 2147-2155. CrossRef Medline

Fernández A, Turrero A, Zuluaga P, Gil P, Maestú F, Campo P, Ortiz T (2006) Magnetoencephalographic parietal delta dipole density in mild cognitive impairment. Arch Neurol 63:427-430. CrossRef Medline

Fischl B, Salat DH, Busa E, Albert M, Dieterich M, Haselgrove C, van der Kouwe A, Killiany R, Kennedy D, Klaveness S, Montillo A, Makris N, Rosen B, Dale AM (2002) Whole brain segmentation: automated labeling of neuroanatomical structures in the human brain. Neuron 33:341355. CrossRef Medline

Garcia-Marin V, Blazquez-Llorca L, Rodriguez JR, Boluda S, Muntane G, Ferrer I, Defelipe J (2009) Diminished perisomatic GABAergic terminals on cortical neurons adjacent to amyloid plaques. Front Neuroanat 3:28. CrossRef Medline

Grimmer T, Wutz C, Drzezga A, Förster S, Förstl H, Ortner M, Perneczky R, Kurz A (2013) The usefulness of amyloid imaging in predicting the clinical outcome after two years in subjects with mild cognitive impairment. Curr Alzheimer Res 10:82-85. CrossRef Medline

Hämäläinen M, Hari R, Ilmoniemi RJ, Knuutila J, Lounasmaa O V (1993) Magnetoencephalography - theory, instrumentation, and applications to noninvasive studies of the working human brain. Rev Mod Phys 65:413497. CrossRef

Hampel H, Teipel SJ, Fuchsberger T, Andreasen N, Wiltfang J, Otto M, Shen Y, Dodel R, Du Y, Farlow M, Möller HJ, Blennow K, Buerger K (2004) Value of CSF beta-amyloid1-42 and tau as predictors of Alzheimer's disease in patients with mild cognitive impairment. Mol Psychiatry 9:705-710. CrossRef Medline 
Hampson M, Driesen NR, Skudlarski P, Gore JC, Constable RT (2006) Brain connectivity related to working memory performance. J Neurosci 26:13338-13343. CrossRef Medline

Hatashita S, Yamasaki H (2013) Diagnosed mild cognitive impairment due to Alzheimer's disease with PET biomarkers of beta amyloid and neuronal dysfunction. PLoS One 8:e66877. CrossRef Medline

Huang C, Wahlund L, Dierks T, Julin P, Winblad B, Jelic V (2000) Discrimination of Alzheimer's disease and mild cognitive impairment by equivalent EEG sources: a cross-sectional and longitudinal study. Clin Neurophysiol 111:1961-1967. CrossRef Medline

Jack CR Jr, Petersen RC, Xu YC, O’Brien PC, Smith GE, Ivnik RJ, Boeve BF, Waring SC, Tangalos EG, Kokmen E (1999) Prediction of AD with MRI-based hippocampal volume in mild cognitive impairment. Neurology 52:1397-1403. CrossRef Medline

Jelic V, Johansson SE, Almkvist O, Shigeta M, Julin P, Nordberg A, Winblad B, Wahlund LO (2000) Quantitative electroencephalography in mild cognitive impairment: longitudinal changes and possible prediction of Alzheimer's disease. Neurobiol Aging 21:533-540. CrossRef Medline

Jiang ZY, Zheng LL (2006) Inter- and intra-hemispheric EEG coherence in patients with mild cognitive impairment at rest and during working memory task. J Zhejiang Univ Sci B 7:357-364. CrossRef Medline

Johns EK, Phillips NA, Belleville S, Goupil D, Babins L, Kelner N, Ska B, Gilbert B, Massoud F, de Boysson C, Duncan HD, Chertkow H (2012) The profile of executive functioning in amnestic mild cognitive impairment: disproportionate deficits in inhibitory control. J Int Neuropsychol Soc 18:541-555. CrossRef Medline

Johnson KA, Moran EK, Becker JA, Blacker D, Fischman AJ, Albert MS (2007) Single photon emission computed tomography perfusion differences in mild cognitive impairment. J Neurol Neurosurg Psychiatry 78: 240-247. Medline

Kaplan E, Goodglass H, Weintraub S (1983) The Boston naming test. Philadelphia: Lea and Febiger.

Khan UA, Liu L, Provenzano FA, Berman DE, Profaci CP, Sloan R, Mayeux R, Duff KE, Small SA (2014) Molecular drivers and cortical spread of lateral entorhinal cortex dysfunction in preclinical Alzheimer's disease. Nat Neurosci 17:304-311. CrossRef Medline

Koenig T, Prichep L, Dierks T, Hubl D, Wahlund LO, John ER, Jelic V (2005) Decreased EEG synchronization in Alzheimer's disease and mild cognitive impairment. Neurobiol Aging 26:165-171. CrossRef Medline

Kramer JH, Nelson A, Johnson JK, Yaffe K, Glenn S, Rosen HJ, Miller BL (2006) Multiple cognitive deficits in amnestic mild cognitive impairment. Dement Geriatr Cogn Disord 22:306-311. CrossRef Medline

Lachaux JP, Rodriguez E, Martinerie J, Varela FJ (1999) Measuring phase synchrony in brain signals. Hum Brain Mapp 8:194-208. CrossRef Medline

Lawton MP, Brody EM (1969) Assessment of older people: self-maintaining and instrumental activities of daily living. Gerontologist 9:179-186. CrossRef Medline

Lehmann C, Koenig T, Jelic V, Prichep L, John RE, Wahlund LO, Dodge Y, Dierks T (2007) Application and comparison of classification algorithms for recognition of Alzheimer's disease in electrical brain activity (EEG). J Neurosci Methods 161:342-350. CrossRef Medline

Lobo A, Ezquerra J, Gómez Burgada F, Sala JM, Seva Díaz A (1979) Cognocitive mini-test (a simple practical test to detect intellectual changes in medical patients) (in Spanish). Actas Luso Esp Neurol Psiquiatr Cienc Afines 7:189-202. Medline

Locatelli T, Cursi M, Liberati D, Franceschi M, Comi G (1998) EEG coherence in Alzheimer's disease. Electroencephalogr Clin Neurophysiol 106: 229-237. CrossRef Medline

Maestú F, Yubero R, Moratti S, Campo P, Gil-Gregorio P, Paul N, Solesio E, del Pozo F, Nevado A (2011) Brain activity patterns in stable and progressive mild cognitive impairment during working memory as evidenced by magnetoencephalography. J Clin Neurophysiol 28:202-209. CrossRef Medline

McKee AC, Au R, Cabral HJ, Kowall NW, Seshadri S, Kubilus CA, Drake J, Wolf PA (2006) Visual association pathology in preclinical Alzheimer disease. J Neuropathol Exp Neurol 65:621-630. Medline

McKhann GM, Knopman DS, Chertkow H, Hyman BT, Jack CR Jr, Kawas CH, Klunk WE, Koroshetz WJ, Manly JJ, Mayeux R, Mohs RC, Morris JC, Rossor MN, Scheltens P, Carrillo MC, Thies B, Weintraub S, Phelps CH (2011) The diagnosis of dementia due to Alzheimer's disease: recommendations from the National Institute on Aging-Alzheimer's Associa- tion workgroups on diagnostic guidelines for Alzheimer's disease. Alzheimers Dement 7:263-269. CrossRef Medline

Moretti DV, Miniussi C, Frisoni GB, Geroldi C, Zanetti O, Binetti G, Rossini PM (2007) Hippocampal atrophy and EEG markers in subjects with mild cognitive impairment. Clin Neurophysiol 118:2716-2729. CrossRef Medline

Moretti DV, Frisoni GB, Fracassi C, Pievani M, Geroldi C, Binetti G, Rossini PM, Zanetti O (2011) MCI patients' EEGs show group differences between those who progress and those who do not progress to AD. Neurobiol Aging 32:563-571. CrossRef Medline

Mori T, Shimada H, Shinotoh H, Hirano S, Eguchi Y, Yamada M, Fukuhara R, Tanimukai S, Zhang MR, Kuwabara S, Ueno S, Suhara T (2014) Apathy correlates with prefrontal amyloid $\beta$ deposition in Alzheimer's disease. J Neurol Neurosurg Psychiatry 85:449-455. CrossRef Medline

Norris G, Tate RL (2000) The behavioural assessment of the dysexecutive syndrome (BADS): ecological, concurrent and construct validity. Neuropsychol Rehabil 10:33-45. CrossRef

Okello A, Koivunen J, Edison P, Archer HA, Turkheimer FE, Någren K, Bullock R, Walker Z, Kennedy A, Fox NC, Rossor MN, Rinne JO, Brooks DJ (2009) Conversion of amyloid positive and negative MCI to AD over 3 years. Neurology 73:754-760. CrossRef Medline

Oldfield RC (1971) The assessment and analysis of handedness: the Edinburgh inventory. Neuropsychologia 9:97-113. CrossRef Medline

Oostenveld R, Fries P, Maris E, Schoffelen JM (2011) FieldTrip: open source software for advanced analysis of MEG, EEG, and invasive electrophysiological data. Comput Intell Neurosci 2011:156869. CrossRef Medline

Peña-Casanova J (1990) Programa Integrado de Exploración Neuropsicológica-Test Barcelona. Protocolo. Barcelona: Masson.

Pereda E, Quiroga RQ, Bhattacharya J (2005) Nonlinear multivariate analysis of neurophysiological signals. Prog Neurobiol 77:1-37. CrossRef Medline

Peters F, Villeneuve S, Belleville S (2014) Predicting progression to dementia in elderly subjects with mild cognitive impairment using both cognitive and neuroimaging predictors. J Alzheimers Dis 38:307-318. CrossRef Medline

Petersen RC, Smith GE, Waring SC, Ivnik RJ, Tangalos EG, Kokmen E (1999) Mild cognitive impairment: clinical characterization and outcome. Arch Neurol 56:303-308. CrossRef Medline

Petersen RC, Doody R, Kurz A, Mohs RC, Morris JC, Rabins PV, Ritchie K, Rossor M, Thal L, Winblad B (2001) Current concepts in mild cognitive impairment. Arch Neurol 58:1985-1992. CrossRef Medline

Pfeffer RI, Kurosaki TT, Harrah CH Jr, Chance JM, Filos S (1982) Measurement of functional activities in older adults in the community. J Gerontol 37:323-329. CrossRef Medline

Pijnenburg YA, v d Made Y, van Cappellen van Walsum AM, Knol DL, Scheltens P, Stam CJ (2004) EEG synchronization likelihood in mild cognitive impairment and Alzheimer's disease during a working memory task. Clin Neurophysiol 115:1332-1339. CrossRef Medline

Poil SS, de Haan W, van der Flier WM, Mansvelder HD, Scheltens P, Linkenkaer-Hansen K (2013) Integrative EEG biomarkers predict progression to Alzheimer's disease at the MCI stage. Front Aging Neurosci 5:58. CrossRef Medline

Prichep LS, John ER, Ferris SH, Rausch L, Fang Z, Cancro R, Torossian C, Reisberg B (2006) Prediction of longitudinal cognitive decline in normal elderly with subjective complaints using electrophysiological imaging. Neurobiol Aging 27:471-481. CrossRef Medline

Reisberg B, Ferris SH, de Leon MJ, Crook T (1982) The Global Deterioration Scale for assessment of primary degenerative dementia. Am J Psychiatry 139:1136-1139. Medline

Reitan R (1958) Validity of the trail making test as an indicator of organic brain damage. Percept Mot Ski 8:271-276. CrossRef

Requena C, Maestú F, Campo P, Fernández A, Ortiz T (2006) Effects of cholinergic drugs and cognitive training on dementia: 2-year follow-up. Dement Geriatr Cogn Disord 22:339-345. CrossRef Medline

Riemenschneider M, Lautenschlager N, Wagenpfeil S, Diehl J, Drzezga A, Kurz A (2002) Cerebrospinal fluid tau and beta-amyloid 42 proteins identify Alzheimer disease in subjects with mild cognitive impairment. Arch Neurol 59:1729-1734. CrossRef Medline

Rosen WG, Terry RD, Fuld PA, Katzman R, Peck A (1980) Pathological verification of ischemic score in differentiation of dementias. Ann Neurol 7:486-488. CrossRef Medline 
Rosenblum M, Pikovsky A, Kurths J (2001) Phase synchronization: from theory to data analysis. Handb Biol Phys 4:279-321. CrossRef

Rossini PM, Del Percio C, Pasqualetti P, Cassetta E, Binetti G, Dal Forno G, Ferreri F, Frisoni G, Chiovenda P, Miniussi C, Parisi L, Tombini M, Vecchio F, Babiloni C (2006) Conversion from mild cognitive impairment to Alzheimer's disease is predicted by sources and coherence of brain electroencephalography rhythms. Neuroscience 143:793-803. CrossRef Medline

Schliebs R, Arendt T (2006) The significance of the cholinergic system in the brain during aging and in Alzheimer's disease. J Neural Transm 113: 1625-1644. CrossRef Medline

Stam CJ, de Haan W, Daffertshofer A, Jones BF, Manshanden I, van Cappellen van Walsum AM, Montez T, Verbunt JP, de Munck JC, van Dijk BW, Berendse HW, Scheltens P (2009) Graph theoretical analysis of magnetoencephalographic functional connectivity in Alzheimer's disease. Brain 132:213-224. CrossRef Medline

Takehara-Nishiuchi K (2014) Entorhinal cortex and consolidated memory. Neurosci Res. Advance online publication. Retrieved August 12, 2014. doi:10.1016/j.neures.2014.02.012. CrossRef Medline

Taulu S, Kajola M (2005) Presentation of electromagnetic multichannel data: the signal space separation method. J Appl Phys 97:124905. CrossRef
Taulu S, Simola J (2006) Spatiotemporal signal space separation method for rejecting nearby interference in MEG measurements. Phys Med Biol 51: 1759-1768. CrossRef Medline

Trzepacz PT, Yu P, Sun J, Schuh K, Case M, Witte MM, Hochstetler H, Hake A (2014) Comparison of neuroimaging modalities for the prediction of conversion from mild cognitive impairment to Alzheimer's dementia. Neurobiol Aging 35:143-151. CrossRef Medline

Uhlhaas PJ, Pantel J, Lanfermann H, Prvulovic D, Haenschel C, Maurer K, Linden DEJ (2008) Visual perceptual organization deficits in Alzheimer's dementia. Dement Geriatr Cogn Disord 25:465-475. CrossRef Medline

Van Veen BD, van Drongelen W, Yuchtman M, Suzuki A (1997) Localization of brain electrical activity via linearly constrained minimum variance spatial filtering. IEEE Trans Biomed Eng 44:867-880. Medline

Warrington E, James M (1991) The visual object and space perception battery. Bury St. Edmunds, UK: Thames Valley Test Company.

Wechsler D (1997) Wechsler Memory Scale, Ed 3 (manual). San Antonio, TX: Psychological Corporation.

Yesavage JA, Brink TL, Rose TL, Lum O, Huang V, Adey M, Leirer VO (1982) Development and validation of a geriatric depression screening scale: a preliminary report. J Psychiatr Res 17:37-49. CrossRef Medline 